\title{
11C Topotecan
}

National Cancer Institute

\section{Source}

National Cancer Institute. 11C Topotecan. NCI Thesaurus. Code C49172.

A semisynthetic derivative of camptothecin, a cytotoxic, quinoline-based alkaloid extracted from the Asian tree Camptotheca acuminata radiolabeled with carbon 11 (11C) with antineoplastic and radiotracer properties. During the S phase of the cell cycle, topotecan inhibits topoisomerase I activity by stabilizing the cleavable complex between topoisomerase I and DNA, resulting in DNA breaks that inhibit DNA replication and trigger apoptotic cell death. Quantitation of 11C topotecan accumulated in tumor tissues by positron emission tomography (PET) may help predict responses to topotecan therapy. 